\title{
A Development and Application of the Fretting Fatigue Test Apparatus
}

\author{
Jun Wang ${ }^{1,2}$, Hong $\mathrm{Xu}^{2}$, Tiexiong Su${ }^{1}$, Huping Mao ${ }^{1}$, Yi Zhang ${ }^{1}$ and Yangang Zhang ${ }^{1}$ \\ ${ }^{1}$ School of Materials Science and Engineering, North University of China, Taiyuan, Shanxi 030051, China \\ ${ }^{2}$ School of Mechanical and Power Engineering, North University of China, Taiyuan, Shanxi 030051, China
}

\begin{abstract}
Fretting fatigue occurs in contacting parts which are subjected to fluctuating loads and very small sliding movements at the same time. Fretting fatigue can significantly reduce the fatigue life of materials. In this investigation, a new device is introduced, which performed using a combination of a servo-hydraulic push-pull fatigue testing machine and a specially designed jig for appropriate positioning of pads. The axial and contact loads are measured by load cells. The functionality of the device is examined by making a comparison between fretting fatigue lives and plain fatigue lives of a number of ZL702A aluminum alloy specimens. The main advantages of the device are its simplicity and cheapness. It can be developed further for high and low temperature tests in future.
\end{abstract}

\section{Introduction}

Fretting is induced by vibrations or the application of bulk fatigue stresses to one or both of the contacting parts and widely occurs at the contact interface between two bodies when there is small amplitude oscillatory relative movement (typically 5-50 micrometers), such as dovetail assemblies in aircraft structures [1], [2], cables in overhead conductors [3] and mine hoist [4], riveted joints [5], prostheses [6], etc. At the edge of the contact there will be a stress singularity which results in early nucleation of cracks at the pad tip. The surface interface cracks are the result of partial slip, friction and etc. within the contact interface. The fretting results in enormous reduction of the endurance limit of a component by half or more, in comparison to the normal fatigue conditions [7].

By far, there is not a commercial universal machine available for fretting fatigue testing. To investigate the characteristics of fretting fatigue, various test apparatus has been developed for special purpose in different fields. Literature of fretting fatigue demonstrates that the fatigue load was imposed mostly by hydraulic actuator and occasionally by position control machine [7]; the contact pressure of fretting specimens is induced through the clamping pads attached to the proving ring, spring or other fretting fixtures. Geometries of the pads are flat, spherical, cylindrical, and bridge-type [3], [4], [8]-[10], but most specimens use flat fretting contact surface. Though there are diverse apparatus for fretting fatigue test, the design has to meet certain requirements to obtain efficient operation and results [11]: (i) the ability to produce a constant normal force between pad and specimen and the visibility of pad and specimen, (ii) a few microns relative movements, (iii) very high stiffness of the fixture, (iv) high precision of measurement.
The research background of the project was the fretting fatigue damage in engine aluminum blocks, and the aim is to provide accurate data to support theoretical design and the practical application of the alloy in vehicle engine. The cylinder blocks are the largest and most intricate single piece, which suffers high clamping forces from bolt assembly and oscillating dynamic forces from bearing load. Fretting wear occurs frequently on the aluminous cylinder block of vehicle engine [12]-[14].

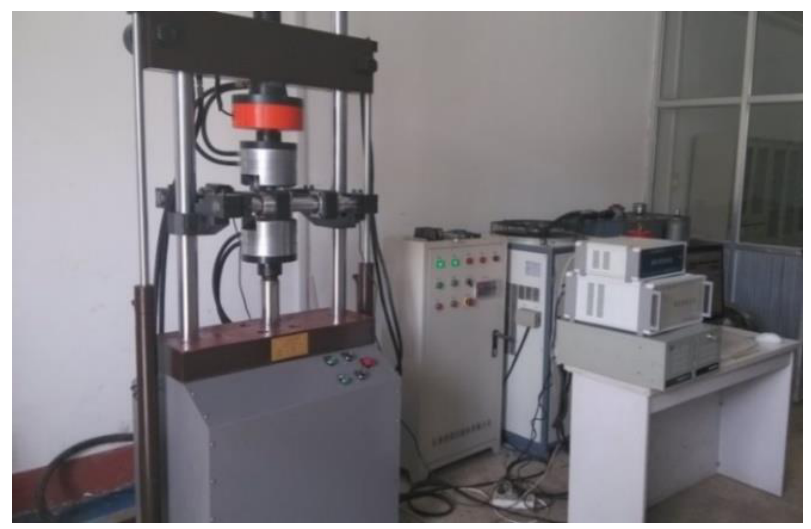

Figure 1. A general view of the fretting fatigue test system.

\section{Test apparatus}

The fretting fatigue test system has been developed by the authors in this investigation. A general view of the system is depicted in Fig. 1. The system consists of three parts: the universal hydraulic fatigue testing device which produces the oscillatory axial displacement, the fretting fatigue test jig through which the pressure is transmitted by two pads to the specimen and the instrumentation. The instrumentation consists of load cells for measuring the contact and axial forces imposed on the specimens, the 
inverter for varying the frequency, and fatigue cycles counter.

As shown in Fig. 2, the schematic of fretting fatigue jig consists of two fixed mounts, two cross girders, two normal load cells, two load adjusting screws, two screw holders, two fretting pad holders and two fretting pads etc. The fixed mounts and cross girders constitutes the supporting platform of fretting fatigue jig, which completely tightened on the two main columns of the servo-hydraulic testing machine by the screws. The other parts of the jig are installed on the platform.
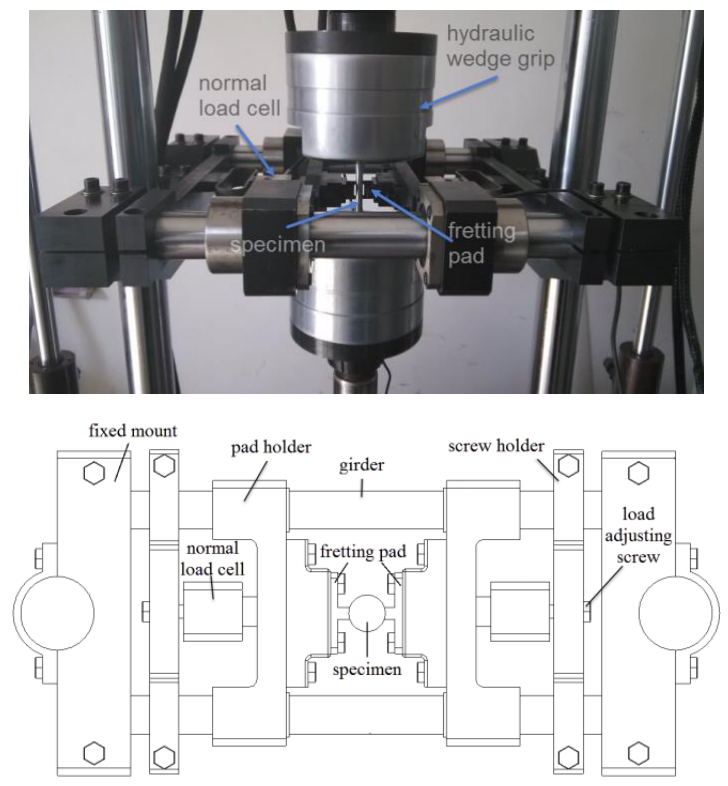

Figure 2. A schematic of the fretting fatigue jig.

The fretting pads fastened on the pad holders which can move along the cross girders always. The adjusting screw holders can move along the cross girders, to facilitate the installation of the specimen before the test. When the specimen installed by the hydraulic wedge grip of the fatigue testing machine, the screw holders and the pad holders can slide to make the fretting pad to press against a flat specimen just. Then the screw holders are fixed on the cross girders.

The normal load is induced by two adjusting screws which impelled the fretting pad clamped the specimen tightly and is real-time measured using two load cells. The load cell digital readings can ensure that the contact loads produced by adjusting screws in two opposite directions are equal and sufficiently accurate.
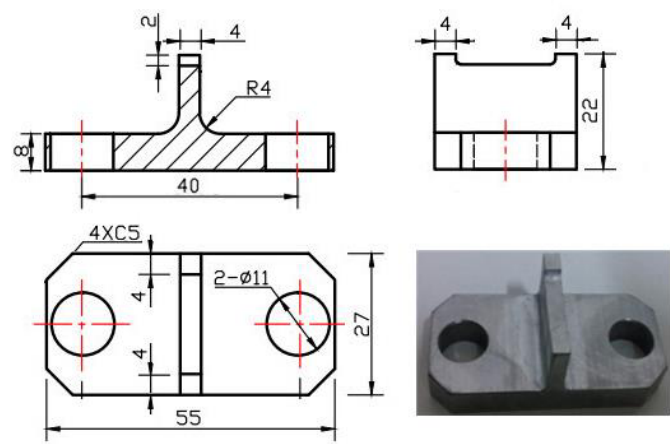

Figure 3. Dimensioned design drawings (dimensions are in $\mathrm{mm}$ ) and entity of the fretting pad which used for transmitting the contact pressure.

Fig. 3 shows the geometry of the fretting pad. Each pad has two contact surfaces with the rectangular section $4 \times 4 \mathrm{~mm}$, the total area of $32 \mathrm{~mm} 2$ (i.e. the contact area of the specimens), with not more than $0.32 \mu \mathrm{m}$ surface roughness which was obtained by using the low stress grind machining and the polishing processes.

To make the laboratory condition closer to actual working condition of engine blocks, the parallelism between the contact surfaces of the specimen and pad was maintained. The fretting fatigue system has the characteristics as below: (i) it can simulate flat-flat or round-flat contact states between specimens and pads by using pads with plane or cylindrical geometries, (ii) it produces a constant normal force of maximum $5 \mathrm{kN}$ between pads and specimens, (iii) it has the visibility of the pads and the specimens, (iv) its normal load be measured using compression load cells with the accuracy of $\pm 1 \%$ FSO (full-scale output), which corresponds to $\pm 0.05 \mathrm{kN}$.

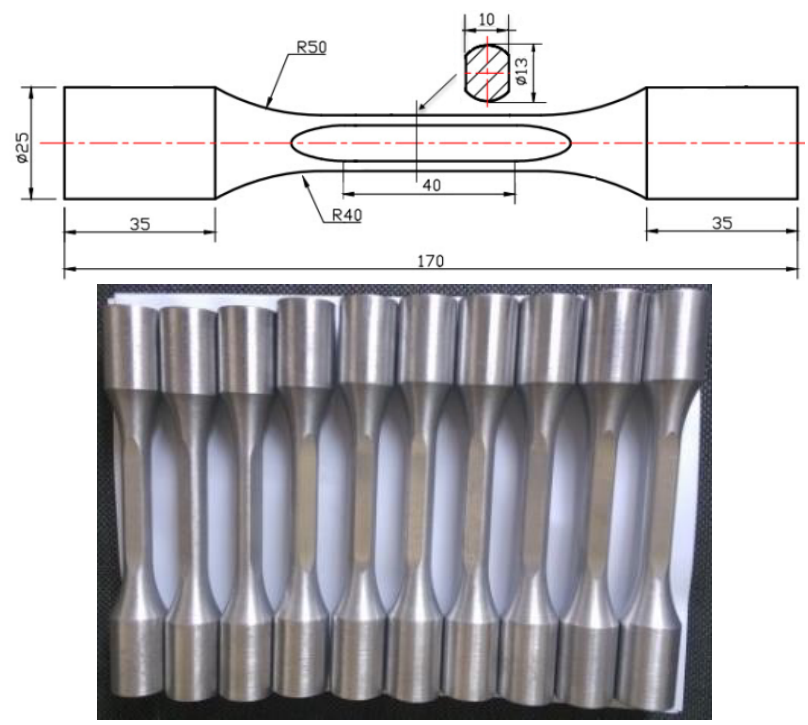

Figure 4. Dimensioned design drawings (dimensions are in $\mathrm{mm}$ ) and entities of the fretting specimen.

\section{Experiment results}

\subsection{Materials and specimens}

ZL702A aluminum alloy was used in this investigation. The material's composition obtained using energy-dispersive X-ray apparatus is $\mathrm{AL} \mathrm{91 \% ,} \mathrm{Si} 7 \%, \mathrm{Cu}$ $1.55 \%, \mathrm{Mg} 0.41 \%$ and $\mathrm{Mn} 0.22 \%$ (wt\%). The flat specimen used in this work had a width of $13 \mathrm{~mm}$, a thickness of $10 \mathrm{~mm}$ and a gauge length of $40 \mathrm{~mm}$. The specimen geometry is shown in Fig. 4. The specimens were processed by solid solution treatment and complete artificial aging. The gauge portions of all specimens were polished with $\mathrm{SiC}$ papers and cleaned with acetone. The surface average roughness of the specimen contact surface in the transverse direction is $0.32 \mu \mathrm{m}$. 


\subsection{Fretting fatigue tests}

In this investigation, the experiments were conducted for stress ratio of $\mathrm{R}=0.1$, frequency of $10 \mathrm{~Hz}$ at a constant contact force of $2 \mathrm{kN}$, and alternating stress amplitudes of $86,104,121,138$ and $156 \mathrm{MPa}$. A number of plain fatigue tests were also performed using the universal fatigue testing machine under the same conditions as stated above for comparison purposes. The results are given in Table I. As the results indicate, the plain and fretting fatigue lives both decrease with the alternating stress increasing. At the same alternating stress, the fretting fatigue life is much lower than the plain fatigue life, and the percent decrease of fatigue life due to fretting is found to be $59 \%$ at average. It is obtained from the experiments that the plain fatigue limit is $89 \mathrm{MPa}$, and the fretting fatigue limit is 42 $\mathrm{MPa}$ at a constant contact force of $2 \mathrm{kN}$, which is only $47 \%$ of plain fatigue limit.

Table 1. Lives obtained from the experiments on fretting and plain fatigue.

\begin{tabular}{|c|c|c|c|}
\hline $\begin{array}{c}\text { Applied } \\
\text { Stress } \\
\sigma_{\max } / \mathrm{MPa}\end{array}$ & $\begin{array}{c}\text { Fretting } \\
\text { fatigue life } \\
\mathrm{N}_{\mathrm{f}} / \text { cycles }\end{array}$ & $\begin{array}{c}\text { Plain fatigue } \\
\text { life } \\
\mathrm{N}_{\mathrm{p}} / \text { cycles }\end{array}$ & $\begin{array}{c}\text { Reduced } \\
\text { proportion of life } \\
\left(1-\mathrm{N}_{\mathrm{f}} / \mathrm{N}_{\mathrm{p}}\right) \%\end{array}$ \\
\hline 86 & 842101 & $>10^{7}$ & - \\
\hline 104 & 73846 & 180588 & 59 \\
\hline 121 & 17908 & 46945 & 62 \\
\hline 138 & 15559 & 35592 & 56 \\
\hline 156 & 811 & 2013 & 60 \\
\hline
\end{tabular}

\subsection{Morphology of fracture and wear Zone}

The fracture and fretting wear surfaces of tested specimens were examined using a scanning electron microscope (SEM). The typical fracture morphologies of the plain and fretting fatigue specimens are illustrated in Fig. 5. The figure indicates that the fracture surface consists of two quite distinct regions: a fatigue zone created by crack propagation and an instant rupture zone which given rise to fracture of specimen when it is sufficiently weakened by the crack zone development. Fig. 5(a) shows that the plain fatigue crack initiated at the intersection of the plane and the cylinder of the specimens (shown by the arrow). The fatigue crack shows a fan-shaped radial propagation. Fig. 5(b) showed cracks of the fretting fatigue specimens originating from the edge of the contact region, expanding to the inner which is under the contact region of the specimen and then radially propagating throughout its thickness.

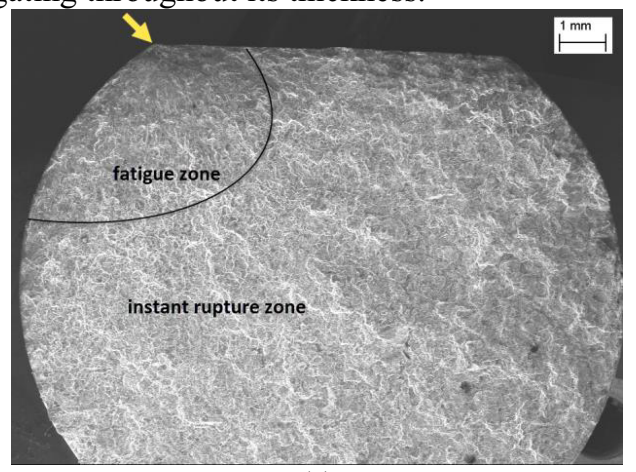

(a)

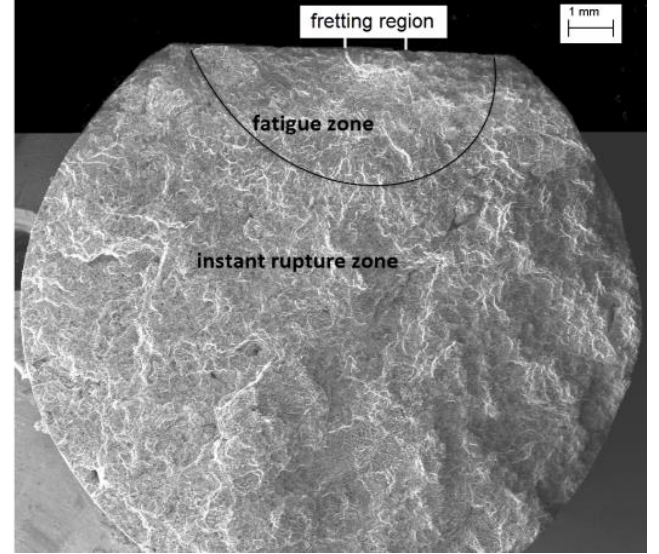

(b)

Figure 5. SEM micrographs of the fracture. (a) plain fatigue test specimen and (b) fretting fatigue test specimen.

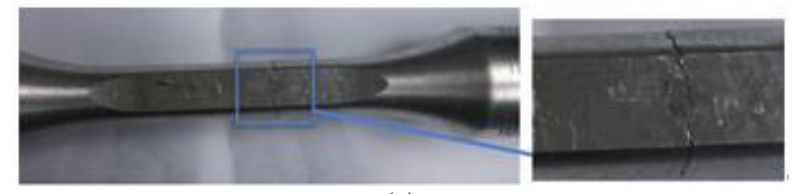

(a)

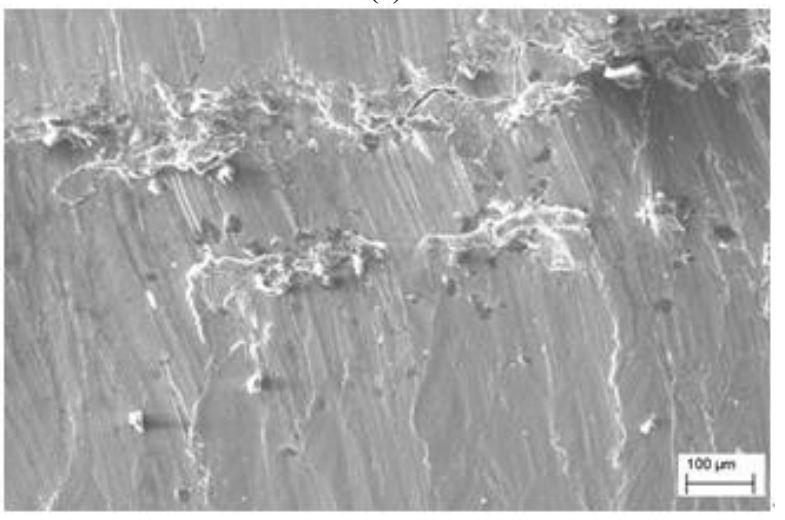

(b)

Figure 6. Fretting wear zone of fretting fatigue specimen. (a) Fretting scar and (b) SEM micrographs of the scar.

Fretting wear zone which are created in the contact area between pads and specimens is shown in Fig.6. Fretting fatigue specimens surface was worn which appears black by fretting and the fracture happened in the most severely worn area. The lamellar structure and plenty of debris presented on the fretting scars of fretting fatigue specimen.

\section{Conclusion}

Based on the universal hydraulic fatigue machine, a new fretting fatigue device typically is developed and manufactured by authors, which has enough accuracy and reliability and has enabled testing condition closer to actual working condition of engine blocks. The device is capable of exerting adjustable axial and contact loads. The frequency of the device can be varied from $1-50 \mathrm{~Hz}$. The functionality of the device is validated by fretting fatigue test results of a number of ZL702A aluminum alloy specimens. The device is well instrumented for varying and measuring axial and contact loads, fatigue cycles, test frequency. 


\section{Acknowledgment}

This work supported by the National Nature Foundation of China (No. 51275489).

\section{References}

1. G.H. Majzoobi, M. Jaleh, Mater. Sci. Eng., A 452-453, 673-681, (2007).

2. D.S. Wei, Y.R. Wang, Eng. Fail. Anal., 25, 144-155, (2012).

3. C.R.F. Azevedo, A.M.D. Henriques, A.R. Pulino Filho, J.L.A. Ferreira, J.A. Araújo, Eng. Fail. Anal., 16, 136-151, (2009).

4. D.G. Wang, D.K. Zhang, Z.F. Zhang, S.R. Ge, Eng. Fail. Anal., 22, 92-112, (2012).

5. L. Zhao, X.C. He, B.Y. Xing, Y. Lu, F.S. Gu, A. Ball, Mater. Des., 87, 1010-1017, (2015).

6. K. Kim, J. Geringer, Wear, 296, 497-503, (2012).
7. G.H. Majzoobi, R. Hojjati, M. Nematian, E. Zalnejad, A.R. Ahmadkhani, E. Hanifepoor, Transactions of the Indian Institute of Metals, 63, 493-497, (2010).

8. G.Q. Wu, Z. Li, W. Sha, H.H. Li, L.J. Huang, Wear, 309, 74-81, (2014).

9. M.P. Szolwinski, T.N. Farris, Wear, 221, 24-36, (1998).

10. R. Sadeler, S. Atasoy, A. Arıc1, Y. Totik, J. Mater. Eng. Performance, 18, 1280-1284, (2009).

11. N. Borms, D. De Schamphelaere, J. De Pauw, P. De Baets, W. De Waele, Sustainable Construction and Design, 370-377, (2011).

12.S. Cha, H. Chang, K.W. Lee, SAE Int. J. Mater. Manuf., 4, 613-619, (2011).

13.Z.M. Wei, J.S. Tan, Z.M. Zhang, S.J. Wen, Z.Z. Chen, J.Y. Li, Vehicle Engine, 162, 56-58, (2006).

14. J.S. Chen, C.Y. Wang, L.S. Bai, J. Mat. Eng., 18, 21-23, (1990). 